\title{
An Overview on Urinary tract infection Diagnostic and Management Approach in Primary Health Care
}

\begin{abstract}
Fatimah Hussain AIShuhayb ${ }^{1 \star}$, Mohammed Ghalab Alanazi ${ }^{2}$, Abdullah Ahmed Alghizzi ${ }^{3}$, Hussam Jameel Khinkar ${ }^{4}$, Fahad Nasser Ali Alnahari $^{5}$, Eman Hassan Hamad Orebi ${ }^{5}$, Jarah Moayad Alobaid ${ }^{6}$, Rajaa Hussain Taliby ${ }^{6}$, Saud Nahed Aldawsari ${ }^{7}$, Hamed Ali Aleidi ${ }^{8}$
\end{abstract}

${ }^{1}$ Faculty of Medicine, King Faisal University, Al Ahsa, KSA. ${ }^{2}$ Dhuhrat Albad'ah PHC, Riyadh, KSA. ${ }^{3}$ Faculty of Medicine, King Saud University, Riyadh, KSA. ${ }^{4}$ Almajid PHC, Jeddah, KSA. ${ }^{5}$ Alghadeer PHC, Riyadh, KSA. ${ }^{6}$ Primary Health Care Center, Riyadh, KSA. ${ }^{7}$ Primary Health Care Center, Wadi Aldawaser, KSA. ${ }^{8}$ Faculty of Medicine, Royal College of Surgeons, Dublin, Ireland.

\section{Abstract}

The urinary tract infection (UTI) counts for many visits to the primary health clinic. It occurs across different age groups and genders with variable rates, nevertheless it spares no one. Knowing this condition from its presentation to management is the key factor for a competent family physician. We aim to review literature searching for the etiology of urinary tract infection, risk factors, diagnosis, clinical presentation, and management regarding this disease. PubMed database was used for articles selection, and the chosen papers had gone through a thorough review. To sum up, most urinary tract infection (UTI) cases can be managed in primary health care clinics. However, understanding the alarming signs and red flags facilitate the process of referral and provides the patients with the best possible care without overwhelming the health care system. Treating the UTI condition is usually done by prescribing proper antibiotics and monitoring the improvement via scheduled appointments.

Keywords: Urinary tract infection, UTI, Urology, Dysuria, E. coli, Urination

\section{INTRODUCTION}

Urinary tract infection (UTI) is one of the most common cases encountered in family care clinics. Hence not all cases should be referred to a specialized clinic, it is rather should be investigated and treated in primary care. Knowing this condition in detail by the family physician will prevent unnecessary referrals that might overwhelm the patient and the healthcare system. The steps start by exploring the patient's history to lead the diagnosis with minimal investigation requests, followed by doing the needed. This condition is common in both adults and children, a new study conducted in Saudi Arabia found that the prevalence among children is close to $25.8 \%$ [1]. Another study suggested that the overall prevalence is $9.9 \%$ with distribution among the age groups as follows; pediatric (18.6\%), adult (59.2\%), and elderly (22.2\%) patients [2]. In this paper we are aiming to shed light upon the diagnosis and management outline that each family practitioner should be aware of.

\section{Materials and Methods}

PubMed database was used for the selection process of relevant articles, and the following keys used in the mesh (("Urinary tract infection"[Mesh]) AND ("Diagnosis"[Mesh] OR "Management"[Mesh] OR "Risk factors"[Mesh] OR "Etiology"[Mesh] OR "Types"[Mesh])). The articles chosen for inclusion were based on meeting one or more of the following criteria: Urinary tract infection or its risk factors, management evaluation process, diagnosis, and/or management. All other articles that did not match the requirements inclusion criterion were excluded.

\section{Review \\ Etiology and Risk Factors}

When it comes to the etiological factors of urinary tract infection (UTI), Escherichia coli (E. coli) is the elephant in the room comprising almost $80 \%$ of all community-acquired UTI [3]. The second most pathogen involved in this type of infection is Staphylococcus saprophyticus, which covers $10 \%$ to $15 \%$, The remaining percent are covered by Klebsiella, Enterobacter, and Proteus species. Different factors play together in order to orchestrate the UTI, many of them concern the host themselves, such as the age group, gender, immunity status, and the presence of foreign objects like a

Address for correspondence: Fatimah Hussain AIShuhayb, Faculty of Medicine, King Faisal University, Al Ahsa, KSA. Fhaa141732@ gmail.com

This is an open-access article distributed under the terms of the Creative Commons Attribution-Non Commercial-Share Alike 3.0 License, which allows others to remix, tweak, and build upon the work non commercially, as long as the author is credited and the new creations are licensed under the identical terms.

How to cite this article: AlShuhayb F H, Alanazi M G, Alghizzi A A, Khinkar H J, Alnahari F N A, Orebi E H H, et al. An Overview on Urinary tract infection Diagnostic and Management Approach in Primary Health Care. Arch. Pharm. Pract. 2022;13(1):157. https://doi.org/10.51847/3neIMfJIpm 
urinary catheter. In the female groups, the etiology may be more complicated as they have multiple risk factors at the same time, this result in having, usually, multi-microbial UTI [4].

\section{Clinical Presentation}

The signs and symptoms of urinary tract infection (UTI) can differ from one case to another. The most common symptoms the patients usually present with are a burning sensation upon urination (dysuria) and an increased frequency in urination [5]. Other symptoms of hesitancy, urgency, and change of the urine nature can also present in some cases [6]. Moreover, uncommon features may rise to the surface if the case was more complicated, like fever and chills and involving upper urinary tract organs. A vigilant physician should always be aware of possible causes in different patients that may explain their symptoms instead of UTI. Generally speaking, attributing the symptoms to a certain population can help with giving an idea of the possible other differentials, such as vaginitis in a perimenopausal and prostatic cause in middleaged men [7].

\section{Types}

The two main categories when it comes to urinary tract infection (UTI) are uncomplicated and complicated UTIs. The former can be described as simple cysto-urethritis resulting from bacterial colonization in the ureter and bladder causing the irritative symptoms, this subtype was named "uncomplicated" due to the good prognosis it has. While the latter digs deeper into the tissue by invading the parenchyma (e.g., pyelonephritis or prostatitis) which usually resulted from a mechanical faulty in the urinary tract like urinary stone obstruction or instrumentation or the patient already suffers from the comorbid disease. This subtype was named "complicated" due to the possible sequelae can turn into, including, but not limited to, sepsis, renal abscess, or acute renal failure $[8,9]$.

\section{Diagnosis}

Urine dipstick is the first initial assessment investigation for those who are suspected to have uncomplicated urinary tract infection (UTI). Most of the cases can be empirically treated based on clinical suspicion and urine dipstick. The clinical suspicion of uncomplicated UTI is defined by the presence of, previously discussed lower urinary tract symptoms, history of dysuria, frequency, and urgency. Nevertheless, to establish an absolute diagnosis of UTI with identification of the causing agent, a urine culture is needed. The indication of urine culture is highly center-dependent according to the availability and the resource in use. Urine culture is usually preserved for some cases like the removal of urine catheter, screening for asymptomatic bacteriuria in pregnant ladies, recurrent uncomplicated UTI, atypical presentation, kidney involvement, systemic symptoms, or UTI in otherwise healthy men. Moreover, some centers opt for urine culture in follow-up to ensure the eradication of the culprit pathogens. The urine culture is very sensitive; thus, a clean catch sample is a must, this can be obtained by a midstream urine sample after proper washing of the area, single catheterization, or more invasively, suprapubic needle aspiration if required. Imaging techniques are, usually, preserved for urology clinic specialists $[10,11]$.

As a family physician, a key skill to master is when to refer. Men are usually less likely to develop UTI for their anatomical privilege, but the gender itself does not usually warrant an immediate referral. Rather, persistent symptoms that are not responding to the usual treatment plan should raise a red flag. Another group to care for when dealt with in the primary clinic is the pediatric group as follows: infants less than three-month of age should be immediately referred, or those who are older but exhibit symptoms of upper UTI. If the infection itself showed: resistance to management, regardless of the gender or age group, severe symptoms, or accompanied with urinary retention. This should warrant an immediate referral to a specialist. Recurrent UTI (defined as more than 3 episodes in the previous 12 months) with: surgically correctable cause, patients' identified risk factor/comorbidity to be treated, or uncertainty of UTI diagnosis [11].

\section{Management}

As the focus in the primary health clinic is to treat uncomplicated cases, a detailed version of the management is to be discussed. European Association of Urology (EAU) in 2021 suggested multiple options to treat uncomplicated urinary tract infection (UTI) [12]. See Table 1. Some of the mentioned antibiotics in the table e.g., nitrofurantoin is mainly excreted in the urine sparing the tissue, thus those types of antibiotics are very good in treating cystitis but fall short in treating pyelonephritis for example. On the other hand, the treatment of complicated UTI is kind of tricky, hospitalization and an intravenous specific broad-spectrum antibiotic is used. With following adjustment of the regimen according to culture results.

\begin{tabular}{|c|c|c|}
\hline \multicolumn{3}{|c|}{$\begin{array}{l}\text { Table 1. Antimicrobial regimen } \\
\text { uncomplicated urinary tract infection }\end{array}$} \\
\hline Antimicrobial & Dosage & Duration \\
\hline \multicolumn{3}{|l|}{ First choice for men } \\
\hline Amoxicillin-clavulanate & $\begin{array}{c}625 \mathrm{mg} / \text { for three times } \\
\text { a day }\end{array}$ & 7 Days \\
\hline \multicolumn{3}{|l|}{ First choice for women } \\
\hline Fosfomycin trometamol & 3 grams as a single dose & 1 Day \\
\hline $\begin{array}{c}\text { Nitrofurantoin } \\
\text { macrocrystal }\end{array}$ & $100 \mathrm{mg}$ for twice a day & 5 Days \\
\hline \multicolumn{3}{|l|}{ Alternative } \\
\hline Ciprofloxacin & $500 \mathrm{mg}$ for twice a day & $\begin{array}{l}\text { Men: } 7 \text { Days } \\
\text { Women: } 3 \\
\text { Days }\end{array}$ \\
\hline Cephalosporin & $\begin{array}{l}\text { Cephalexin } 500 \mathrm{mg} \text { for } \\
\text { four times a day } \\
\text { Cefuroxime } 500 \mathrm{mg} \text { for } \\
\text { twice a day }\end{array}$ & 3 Days \\
\hline
\end{tabular}


If $\mathbf{E}$. coli resistance is endemic (20\%)

Co-trimoxazole
Men: 7 Days

Women: 3 Days

\section{CONCLUSION}

The urinary tract infection is one of the most common diseases encountered in the primary clinic practice. As much as it is, mostly, easy to detangle and manage, sometimes the symptoms can be tricky and have more than what the eye can see. Knowing the differences between the uncomplicated and complicated cases is vital to determine whether the patient should be treated in outpatient primary care or transferred to the specialist clinic. A well-rounded management plan for the patient includes prescribing empirical antibiotics according to their respective gender and follow-up meetings to ensure the eradication of the infection.

\section{ACKNOWLEDGMENTS: None CONFLICT OF INTEREST: None FINANCIAL SUPPORT: None ETHICS STATEMENT: None}

\section{REFERENCES}

1. Alrasheedy M, Abousada HJ, Abdulhaq MM, Alsayed RA, Alghamdi KA, Alghamdi FD, et al. Prevalence of urinary tract infection in children in the kingdom of Saudi Arabia. Arch Ital Urol Androl. 2021;93(2):206-10. doi:10.4081/aiua.2021.2.206
2. Alanazi MQ. An evaluation of community-acquired urinary tract infection and appropriateness of treatment in an emergency department in Saudi Arabia. Ther Clin Risk Manag. 2018;14:2363-73. doi:10.2147/TCRM.S178855

3. Narimene EK, Zohra SF, Mustapha R. In Vitro Study of the Antimicrobial Effect of Synthesized Copolymer Compounds Against Staphylococcus aureus and Escherichia coli strains. Pharmacophore. 2019;10(3):82-8.

4. Ronald A. The etiology of urinary tract infection: traditional and emerging pathogens. Am J Med. 2002;113(1):14-9. doi:10.1016/s0002-9343(02)01055-0

5. Kalani L, Rashidi N, Mehranfard S, Bahrami H, Majidipour N, Moghaddam AS, et al. Epidemiology of the Urinary Stones: A 6-Year Retrospective Study at Dezful-Iran. Int J Pharm Phytopharmacol Res. 2020;10(4):79-85.

6. Gallagher DJ, Montgomerie JZ, North JD. Acute infections of the urinary tract and the urethral syndrome in general practice. Br Med J. 1965;1(5435):622-6. doi:10.1136/bmj.1.5435.622

7. Michels TC, Sands JE. Dysuria: Evaluation and Differential Diagnosis in Adults. Am Fam Physician. 2015;92(9):778-86.

8. Wagenlehner FME, Hoyme U, Kaase M, Fünfstück R, Naber KG, Schmiemann G. Uncomplicated urinary tract infections. Dtsch Arztebl Int. 2011;108(24):415-23. doi:10.3238/arztebl.2011.0415

9. Nicolle LE. Complicated urinary tract infection in adults. Can J Infect Dis Med Microbiol. 2005;16(6):349-60. doi:10.1155/2005/385768

10. Najar MS, Saldanha CL, Banday KA. Approach to urinary tract infections. Indian J Nephrol. 2009;19(4):129-39. doi:10.4103/09714065.59333

11. Tan CW, Chlebicki MP. Urinary tract infections in adults. Singapore Med J. 2016;57(9):485-90. doi:10.11622/smedj.2016153

12. Grabe M, Bjerklund-Johansen T, Botto H. EAU Guidelines. Edn presented at the EAU Annual Congress Milan Italy 2021. Published online 2021. https://uroweb.org/wp-content/uploads/EAU-Guidelineson-Urological-infections-2021.pdf 